\title{
Appropriate Dynamic-Stall Models for Performance Predictions of VAWTs with NLF Blades
}

\author{
CHRISTIAN MASSON *, CHRISTOPHE LECLERC and ION PARASCHIVOIU \\ Bombardier Aeronautical Chair, École Polytechnique, Montréal, Canada, H3C 3 A7 \\ (Received 8 February 1997; In final form 20 February 1997)
}

\begin{abstract}
This paper illustrates the relative merits of using Natural Laminar Flow (NLF) airfoils in the design of Vertical Axis Wind Turbines (VAWT). This is achieved by the application of the double-multiple-streamtube model of Paraschivoiu to the performance predictions of VAWTs equipped with conventional and NLF blades. Furthermore, in order to clearly illustrate the potential benefit of reducing the drag, the individual contributions of lift and drag to power are presented. The dynamic-stall phenomena are modelled using the method of Gormont as modified by several researchers. Among the various implementations of this dynamic-stall model available in the literature, the most appropriate and general for NLF applications has been identified through detailed comparisons between predicted performances and experimental data. This selection process is presented in the paper. It has been demonstrated that the use of NLF airfoils in VAWT applications can lead to significant improvements with respect to conventional design only in a very low wind speed range, the extent of which is negligible with respect to the VAWT operational wind speeds.
\end{abstract}

Keywords: VAWT, Double-Multiple-Streamtube Model, Dynamic Stall, NLF Airfoil

\section{INTRODUCTION}

The Vertical Axis Wind Turbine (VAWT) offers a mechanically and structurally simple method of harnessing the energy of the wind. This simplicity, however, does not extend to the rotor aerodynamics. The blade elements operate in both unstalled and stalled conditions with aerodynamic stall providing the rotor inherent power regulation. The blade elements encounter their own wakes and those generated by other elements. These features combine to make the thorough analysis of Darrieus rotor aerodynamics a challenging undertaking. However, various aerodynamic methods, appropriate for the conception of turbines, are available to designers. These models can be classified into

*Corresponding author. Present address: École de technologie supérieure, 1100 rue Notre-Dame Ouest, Montréal, Canada, $\mathrm{H} 3 \mathrm{C} 1 \mathrm{~K} 3$. 
three categories: (i) Navier-Stokes/source-in-cell models (Rajagopalan et al. [1985]), (ii) vortex models (Gohard [1978], Strickland et al. [1980]), and (iii) streamtube models (Templin [1974], Strickland [1975], Paraschivoiu [1988]).

The successful design of an efficient rotor can be obtained only when appropriate airfoil sections have been selected. Most VAWTs currently operating worldwide use blades of symmetrical NACA airfoil series. It has been proposed to use Natural Laminar Flow (NLF) airfoils to increase the efficiency of the VAWT. NLF airfoils typically can maintain a laminar flow up to $50 \%$ chord through favourable pressure gradients, which results in a significant reduction of the airfoil drag.

This paper illustrates the benefits and losses resulting from using NLF airfoils on VAWT blades. To achieve this goal, the streamtube model of Paraschivoiu [1988] is used to predict the performance of VAWTs equipped with blades of various airfoil shapes. The airfoil shapes considered are the conventional airfoils NACA 0015 and NACA 0018, and the NLF airfoils designed at Sandia: SNLA 0015/47 and SNLA 0018/50. The dynamic stall characteristics of NLF airfoils are significantly different from those of conventional airfoils. Therefore, the dynamic stall models included in the digital version of the streamtube model for Paraschivoiu [1988], which have been validated mainly on conventional airfoils, have been revised and validated for NLF airfoils. This validation process is also presented in the paper. In order to clearly illustrate the potential benefit of reducing the airfoil drag, the individual contributions of lift and drag to power are presented.

\section{DOUBLE-MULTIPLE-STREAMTUBE MODEL}

In the double-multiple-streamtube model it is assumed that the vertical-axis wind turbine can be represented by a pair of actuator disks in tandem at each level of the rotor. The different induced velocities are considered at the upstream and downstream halves of the volume swept by the rotor. The flow through the wind turbine is considered to be subdivided into a large number of aerodynamically independent streamtubes. The effects of turbulence or gustiness are neglected and only the mean wind speed is considered.

The flow in each streamtube is considered to be acted upon by two actuator disks: the first one representing the upwind half of the surface swept by the rotor blades $(-\pi / 2 \leq \theta \leq \pi / 2)$, and the second one representing the downwind half of the rotor $(\pi / 2 \leq \theta \leq 3 \pi / 2)$. As a result of the forces exerted by the actuator disks on the fluid, its velocity changes along the streamtube. The induced velocity decreases in the freestream-velocity direction.

Along any given streamtube the fluid velocity variation is discretised into five different velocities, as shown in Fig. 1. For a given freestream velocity $V_{\infty}(Z)$ we have the following velocity variations along the corresponding streamtube:

$$
\begin{aligned}
V & =u V_{\infty}(Z), \\
V_{e} & =(2 u-1) V_{\infty}(Z), \\
V^{\prime} & =u^{\prime}(2 u-1) V_{\infty}(Z), \\
V^{\prime \prime} & =\left(2 u^{\prime}-1\right)(2 u-1) V_{\infty}(Z),
\end{aligned}
$$

where $u$ and $u^{\prime}$ are the interference factors.

By applying the momentum equation to control volumes that contain the actuator disks, the forces on the disks and the induced velocities can be determined. The local relative velocity $W$ and the local angle of attack $\alpha$ for the upstream half-cycle of the rotor, $-\pi / 2 \leq \theta \leq \pi / 2$, are given by (see Fig. 1):

$$
\begin{aligned}
& W^{2}=V^{2}\left[(X-\sin \theta)^{2}+\cos ^{2} \theta \cos ^{2} \delta\right] \\
& \qquad \alpha=\arcsin \left[\frac{\cos \theta \cos \delta}{\sqrt{(X-\sin \theta)^{2}+\cos ^{2} \theta \cos ^{2} \delta}}\right], \\
& \text { where } \quad X=\frac{\omega r}{V}
\end{aligned}
$$

and $\omega$ is the turbine rotational speed. 


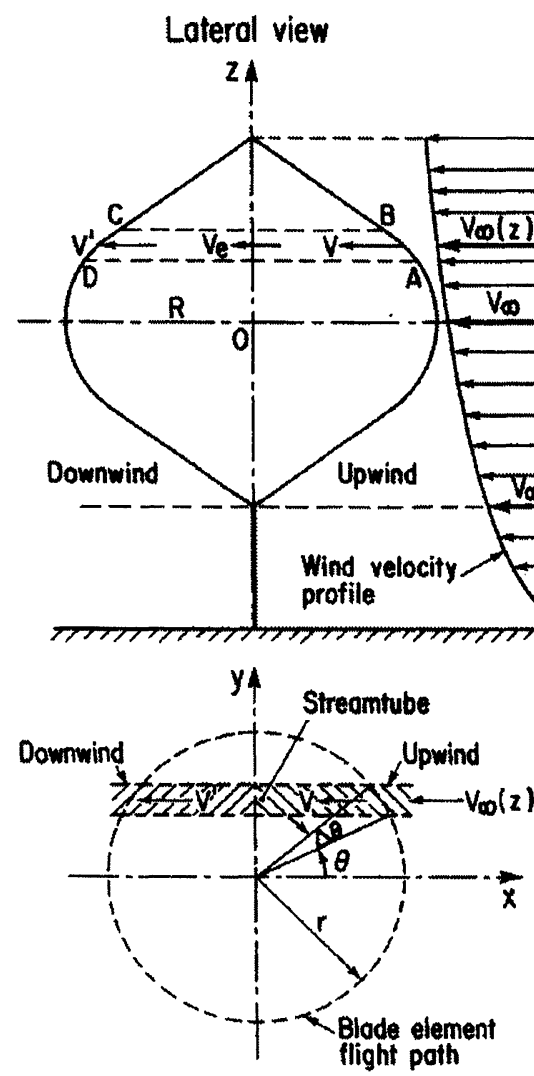

Plan view
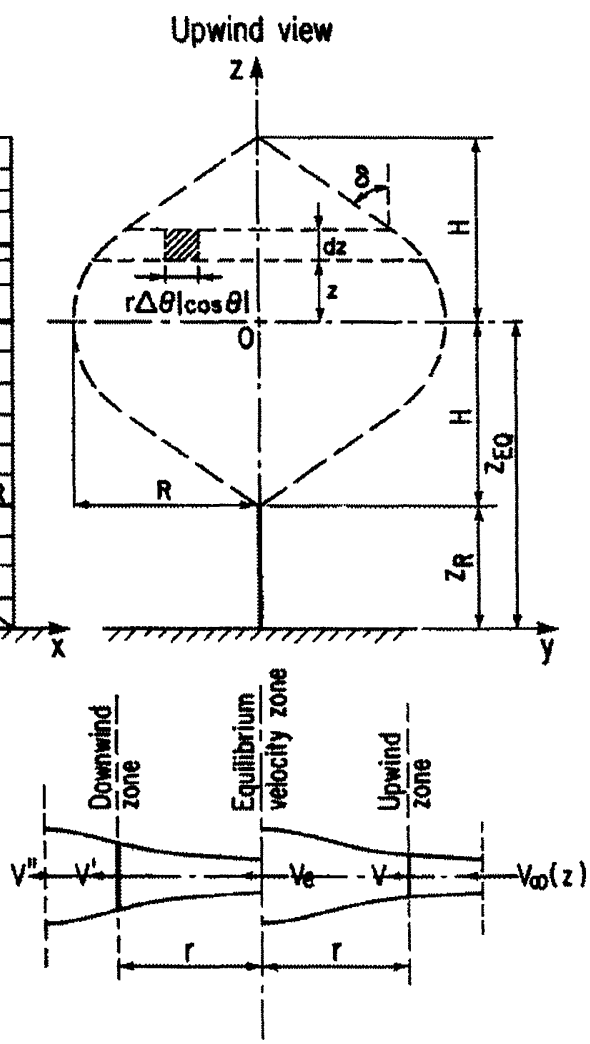

Rotor element $A B C D$ replaced by two actuator disks in tandem

FIGURE 1 Principle of the Double-Multiple-Streamtube Model.

The nondimensional normal and tangential forces as a function of the azimuthal angle $\theta$ are:

$$
\begin{aligned}
F_{N X}(\theta) & =\frac{c}{S} \int_{Z_{R}}^{Z_{R}+2 H}\left(\frac{W}{V_{\infty}}\right)^{2} C_{N} \mathrm{~d} Z, \\
F_{T}(\theta) & =\frac{c}{S} \int_{Z_{R}}^{Z_{R}+2 H}\left(\frac{W}{V_{\infty}}\right)^{2}\left(\frac{C_{T}}{\cos \delta}\right) \mathrm{d} Z,
\end{aligned}
$$

where $c$ is the local airfoil chord and $S$ is the plane area enclosed by the blades. The normal and tangential force coefficients of the blade section are given by

$$
\begin{aligned}
& C_{N}=C_{L} \cos \alpha+C_{D} \sin \alpha, \\
& C_{T}=C_{L} \sin \alpha-C_{D} \cos \alpha,
\end{aligned}
$$

where the lift coefficient $C_{L}$ and the drag coefficient $C_{D}$ are obtained by interpolating two-dimensional static test data using both the local Reynolds number and the local angle of attack. These coefficients are used up to an angle close to the static stall angle from which point a dynamic-stall model is considered to estimate the dynamic lift and drag coefficients. The dynamic-stall model used in this work is presented in the next section.

The upwind interference factor $u(\theta)$ is given by (Paraschivoiu [1988])

$$
K[1-u(\theta)] \cos \theta=u(\theta) f(\theta)
$$

where $K=\frac{8 \pi r}{N c}$,

$$
f(\theta)=\left(\frac{W}{V}\right)^{2}\left[C_{N} \cos \theta+C_{T}\left(\frac{\sin \theta}{\cos \delta}\right)\right]
$$

and $N$ is the number of blades. The upwind halfcycle of the rotor is divided into several angular 
tubes $\Delta \theta$ and for each of these tubes a constant induced velocity is assumed, i.e. $u(\Theta)=$ const for $\theta-\Delta \theta / 2 \leq \Theta \leq \theta+\Delta \theta / 2$. Under this assumption, Eq. (7) can be integrated to obtain:

$$
u(\theta)=\frac{K K_{0}}{K K_{0}+\int_{\theta-\Delta \theta / 2}^{\theta+\Delta \theta / 2} f(\Theta) \mathrm{d} \Theta},
$$

where $K_{0}=\sin (\theta+\Delta \theta / 2)-\sin (\theta-\Delta \theta / 2)$. The integral in Eq. (9) is computed numerically.

A similar procedure is applied for the downstream half-cycle of the rotor, $\pi / 2 \leq \theta \leq 3 \pi / 2$. Finally, the lift and drag contributions to the average torque coefficient are, respectively,

$$
\begin{gathered}
\left(C_{Q}\right)_{L}=\frac{N c}{2 \pi S R} \int_{-\pi / 2}^{3 \pi / 2} \int_{Z_{R}}^{Z_{R}+2 H} C_{L} \sin \alpha\left(\frac{W}{V_{\infty}}\right)^{2} \\
\times\left(\frac{r}{\cos \delta}\right) \mathrm{d} Z \mathrm{~d} \theta \\
\left(C_{Q}\right)_{D}=\frac{N c}{2 \pi S R} \int_{-\pi / 2}^{3 \pi / 2} \int_{Z_{R}}^{Z_{R}+2 H} C_{D} \cos \alpha\left(\frac{W}{V_{\infty}}\right)^{2} \\
\times\left(\frac{r}{\cos \delta}\right) \mathrm{d} Z \mathrm{~d} \theta
\end{gathered}
$$

The lift contribution to the power $P_{L}$ and the drag losses $P_{D}$ for the entire rotor are:

$$
\begin{aligned}
& P_{L}=\frac{1}{2} \rho_{\infty} V_{\infty}^{3} S\left(C_{Q}\right)_{L} \frac{\omega R}{V_{\infty}}, \\
& P_{D}=\frac{1}{2} \rho_{\infty} V_{\infty}^{3} S\left(C_{Q}\right)_{D} \frac{\omega R}{V_{\infty}},
\end{aligned}
$$

The mechanical power of the rotor is finally given by the difference between the lift contribution to power and the drag losses:

$$
P=P_{L}-P_{D} .
$$

A measure of the efficiency of the rotor blade to produce power is the ratio of the drag losses to the lift contribution to power. This ratio will be referred to as the relative drag losses.

\section{DYNAMIC-STALL MODEL}

Dynamic stall is a complex unsteady phenomenon related to an airfoil undergoing large and rapid variations of the angle of attack with time. In such conditions, the dynamic lift and drag characteristics present an hysteresis response which is completely different from the static coefficients. Therefore, the aim of a dynamic-stall model is to propose a methodology to compute the dynamic characteristics from the available experimental static coefficients. In this work, various adaptations of the dynamic-stall model of Gormont [1973] are used for the performance predictions at low tip speed ratios. This model has been developed for helicopter blades and several implementations have been proposed for VAWTs (Strickland et al. [1980], Massé [1981], Berg [1983], Paraschivoiu et al. [1988]). This section describes the original dynamicstall model of Gormont along with the various adaptations for VAWTs.

\subsection{Gormont Model}

The Gormont model empirically mimics the hysteresis response of an airfoil by defining a reference angle of attack at which the static two-dimensional coefficient data is considered. This reference angle of attack is different from the geometric angle of attack (see Eq. (3)) and is given by the following expression:

$$
\alpha_{r e f}=\alpha-K_{1} \Delta \alpha,
$$

where

$$
K_{1}= \begin{cases}1 & \text { when } \dot{\alpha} \geq 0, \\ -0.5 & \text { when } \dot{\alpha}<0,\end{cases}
$$

$\Delta \alpha= \begin{cases}\gamma_{1} S & \text { when } S \leq S_{C}, \\ \gamma_{1} S_{C}+\gamma_{2}\left(S-S_{C}\right) & \text { when } S>S_{C},\end{cases}$

$$
S=\sqrt{\left|\frac{c \dot{\alpha}}{2 W}\right|} \quad S_{C}=0.06+1.5\left(0.06-\frac{t}{c}\right),
$$

$\gamma_{1}= \begin{cases}\gamma_{2} / 2 & \text { for lift characteristic, } \\ 0 & \text { for drag characteristic, }\end{cases}$

$$
\gamma_{2}=\gamma_{\mathrm{mx}} \max \left\{0, \min \left[1, \frac{M-M_{2}}{M_{1}-M_{2}}\right]\right\},
$$


TABLE I Specific forms of $M_{1}, M_{2}$, and $\gamma_{\mathrm{mx}}$

\begin{tabular}{lcc}
\hline & Lift Characteristic & Drag Characteristic \\
\hline$M_{1}$ & $0.4+5.0(0.06-(t / c))$ & 0.2 \\
$M_{2}$ & $0.9+2.5(0.06-(t / c))$ & $0.7+2.5(0.06-(t / c))$ \\
$\gamma_{\mathrm{mx}}$ & $1.4-6.0(0.06-(t / c))$ & $1.0-2.5(0.06-(t / c))$ \\
\hline
\end{tabular}

$M$ is the Mach number, $\dot{\alpha}$ is the time derivative of $\alpha$, and $t / c$ is the airfoil relative thickness. The expressions for $M_{1}, M_{2}$, and $\gamma_{\mathrm{mx}}$ are presented in Table I.

Finally, the dynamic coefficients are given by:

$$
C_{L}^{d y n}=C_{L}\left(\alpha_{0}\right)+m\left(\alpha-\alpha_{0}\right) \quad C_{D}^{d y n}=C_{D}\left(\alpha_{r e f}\right),
$$

where

$$
m=\min \left[\frac{C_{L}\left(\alpha_{r e f}\right)-C_{L}\left(\alpha_{0}\right)}{\alpha_{r e f}-\alpha_{0}}, \frac{C_{L}\left(\alpha_{s s}\right)-C_{L}\left(\alpha_{0}\right)}{\alpha_{s s}-\alpha_{0}}\right]
$$

$\alpha_{0}$ is any convenient angle of attack but is typically taken as the zero-lift angle of attack. $\alpha_{s s}$ is the static-stall angle of attack. It is important to note here that in this model, the value of the reference angle of attack is different for the lift and the drag. This is clearly presented in the various expressions for $M_{1}, M_{2}, \gamma_{\mathrm{mx}}$, and $\gamma_{2}$ (see Table I and Eq. (18)).

\subsection{Adaptation of Strickland et al.}

Strickland et al. [1980] were among the first to propose an adaptation of the Gormont model for VAWTs. In their implementation, the flow is assumed to be incompressible. Furthermore, since the relative thickness of airfoils typically used for VAWTs is more than $12 \%, S_{C}$ was set to zero. The expressions for the dynamic coefficients were specialized for symmetrical airfoils. This simplified Gormont model is applied only when $\alpha \geq \alpha_{s s}$.

\subsection{Adaptation of Paraschivoiu et al.}

Since it was proven experimentally that high-level turbulence delays the occurrence of the dynamic stall, Laneville et al. [1985]), it has been suggested to apply the adaptation of Strickland et al. [1980] only in regions of low turbulence (Paraschivoiu et al. [1988]). These low-turbulence regions have been localised based on water tunnel visualizations performed at the Institut de Mécanique et Statistique de la Turbulence (IMST) in Marseille, France (Brochier et al. [1986]).

\subsection{Modification of Berg}

As noted before, the Gormont model has been developed for helicopter blades. In such applications, the maximum angle of attack reached is much lower than in the case of VAWT blades. This has led to the speculation that the Gormont model overpredicts the effects of the dynamic stall on VAWT performances. In order to avoid this overprediction, Massé [1981] has proposed to compute modified dynamic coefficients based on a linear interpolation between the dynamic coefficients predicted by the Gormont model and the static coefficients as follows:

$$
\begin{gathered}
C_{L}^{\text {mod }}=\left\{\begin{array}{c}
C_{L}+\left[\frac{A_{M} \alpha_{s s}-\alpha}{A_{M} \alpha_{s s}-\alpha_{s s}}\right]\left(C_{L}^{d y n}-C_{L}\right), \\
\text { when } \alpha \leq A_{M} \alpha_{s s}, \\
C_{L}, \quad \text { when } \alpha>A_{M} \alpha_{s s},
\end{array}\right. \\
C_{D}^{\text {mod }}=\left\{\begin{array}{c}
C_{D}+\left[\frac{A_{M} \alpha_{s s}-\alpha}{A_{M} \alpha_{s s}-\alpha_{s s}}\right]\left(C_{D}^{d y n}-C_{D}\right), \\
\text { when } \alpha \leq A_{M} \alpha_{s s}, \\
C_{D}, \quad \text { when } \alpha>A_{M} \alpha_{s s},
\end{array}\right.
\end{gathered}
$$

where $A_{M}$ is an empirical constant. Massé has proposed a value of 1.8 for $A_{M}$. This adaptation of Massé is also different from that of Strickland since the effect of the local Mach number included in the original Gormont model is kept.

Starting with Massé's modification, Berg [1983] has proposed to use $A_{M}=6$. This value of $A_{M}$ gives good agreement between the predicted and experimental performances of the VAWT Sandia 17-m. Berg has also proposed to define $\alpha_{s s}$ to be the angle at which the variation of the lift coefficient with respect to the angle of attack begins to depart from the linear behaviour. 


\section{RESULTS AND DISCUSSION}

The results presented in this section have been selected to illustrate: (i) the accuracy of the various Gormont model adaptations presented in the previous section, and (ii) the merits of using NLF airfoils in VAWT applications.

\subsection{Accuracy of the Various Gormont Model Adaptations}

Figures 2-7 show comparisons between experimental data and performance predictions using the various implementations of the Gormont dynamicstall model. Calculations have been undertaken on three specific VAWTs. The first one is the Sandia $17-\mathrm{m}$ which is a rotor equipped with two blades having a conventional NACA 0015 airfoil. Figures 2 and 3 show the performance of the Sandia 17-m operating at the rotational speeds of 42.2 and $46.6 \mathrm{rpm}$. Figures 4 and 5 show the performance of the Hydro-Quebec Magdalen Islands rotor, equipped with conventional NACA 0018 blades, and operating at 29.4 and $36.6 \mathrm{rpm}$. Finally, Figures 6 and 7 show the performance of the Sandia 34-m VAWT. This rotor is equipped with two segmented blades: the blade profile is a NLF SNLA 0018 near the middle region while a conventional NACA 0021 is used in the root regions. Comparisons at the rotational speeds of 28 and $34 \mathrm{rpm}$ are presented in Figures 6 and 7, respectively. These figures contain a large amount of information concerning the behaviour of the various adaptations of the Gormont dynamic-stall model. In the following discussion, only the general trends will be discussed.

The implementation proposed by Strickland et al. has the tendency to overpredict the mechanical power at large wind velocities. This behaviour can be clearly seen in the case of the Sandia $17-\mathrm{m}$ rotor. For this rotor, more accurate results are obtained when the modifications proposed by Paraschivoiu et al. [1988], which take into account the effects of the turbulence level on the dynamic stall, are included. The improvement produced by

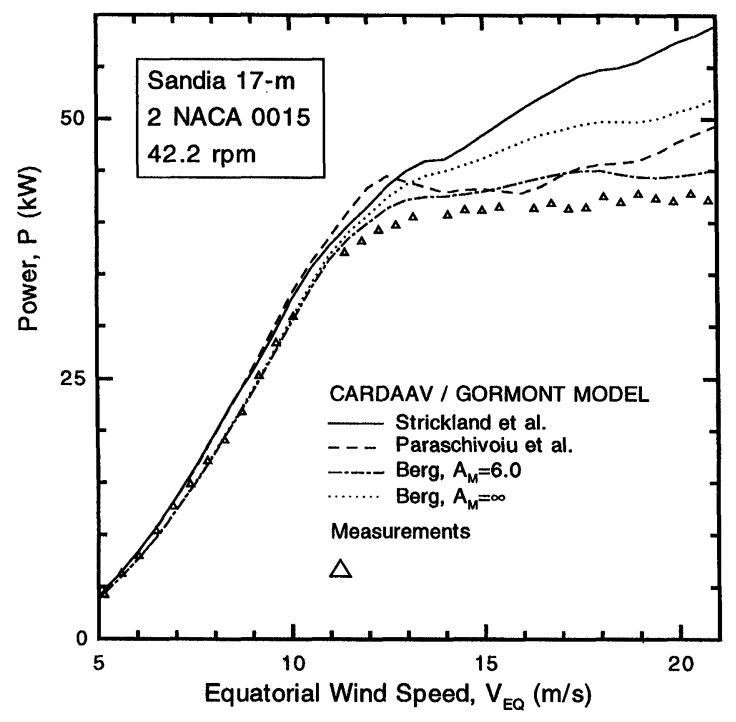

FIGURE 2 Gormont-model adaptations: sandia 17-m at $42.2 \mathrm{rpm}$.

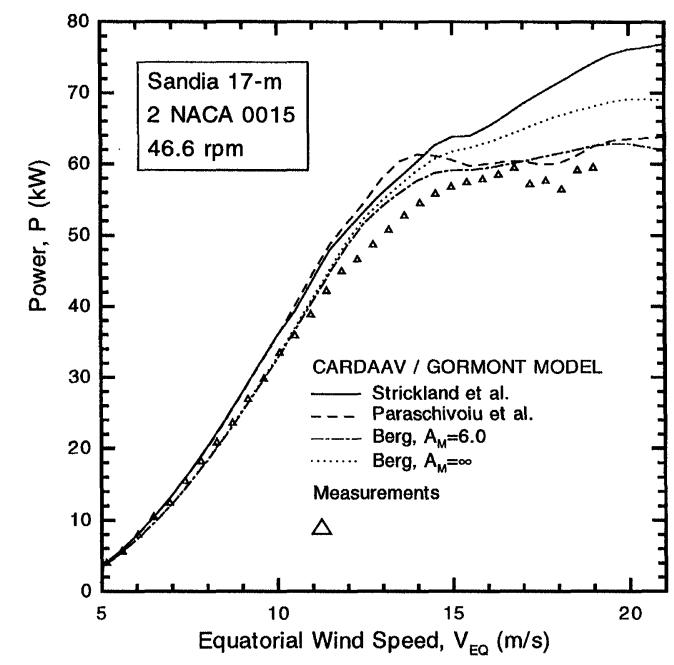

FIGURE 3 Gormont-model adaptations: sandia $17-\mathrm{m}$ at $46.6 \mathrm{rpm}$.

the inclusion of the influence of the turbulence level is not as significant in the case of the Magdalen Islands and Sandia 34-m rotors. It should be noted that the zones of low turbulence level defined in the implementation are based on the water-tunnel visualizations and are invariant. However, it is expected that the extent and position of these 


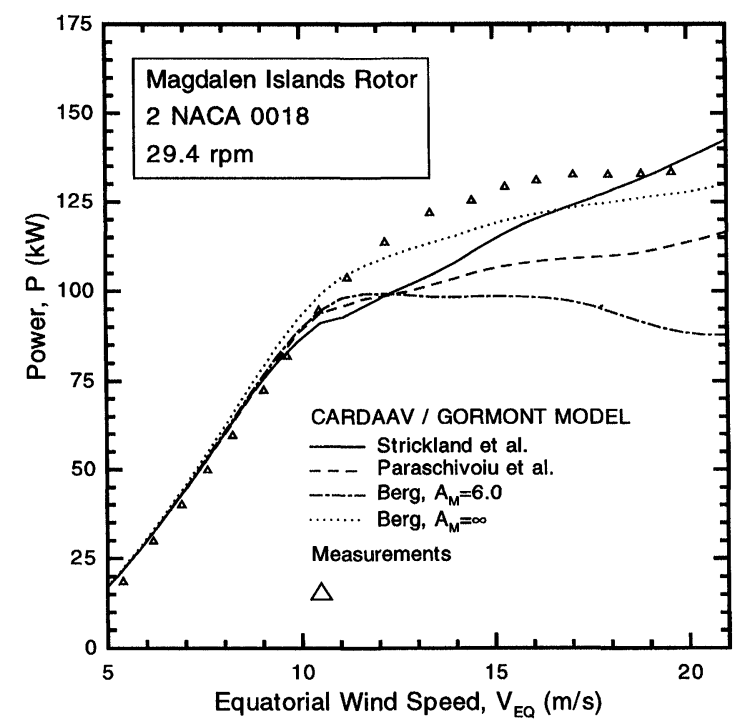

FIGURE 4 Gormont-model adaptations: Magdalen Islands rotor at $29.4 \mathrm{rpm}$.

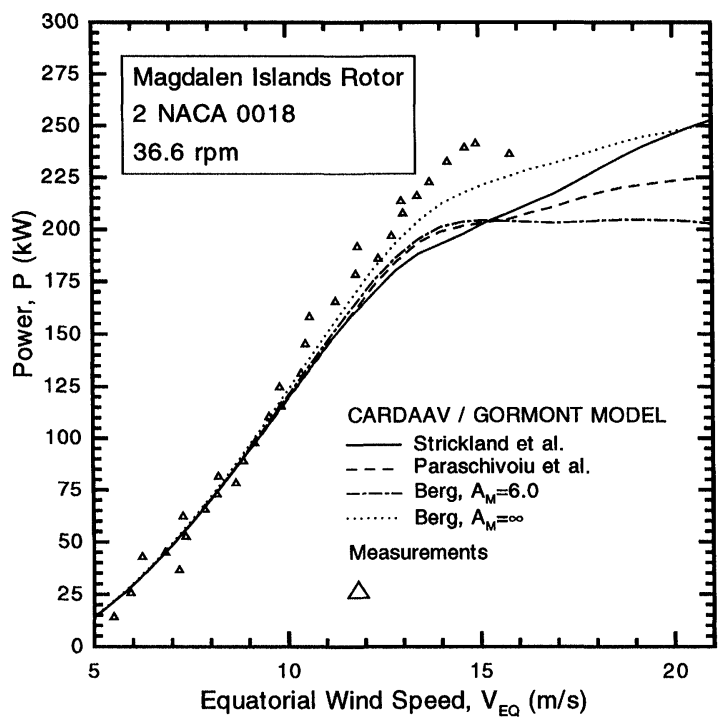

FIGURE 5 Gormont-model adaptations: Magdalen Islands rotor at $36.6 \mathrm{rpm}$.

low-turbulence zones are influenced by the operational conditions. The neglect of these variations seems to limit the range of applicability of this adaptation (Paraschivoiu [1988]). It is worth noticing at this point that the results produced by

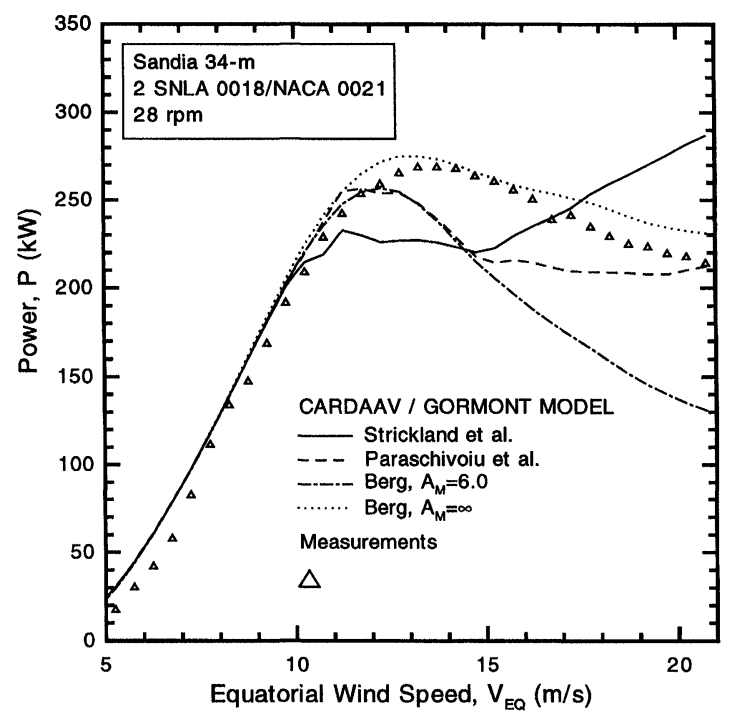

FIGURE 6 Gormont-model adaptations: Sandia 34-m at $28.0 \mathrm{rpm}$.

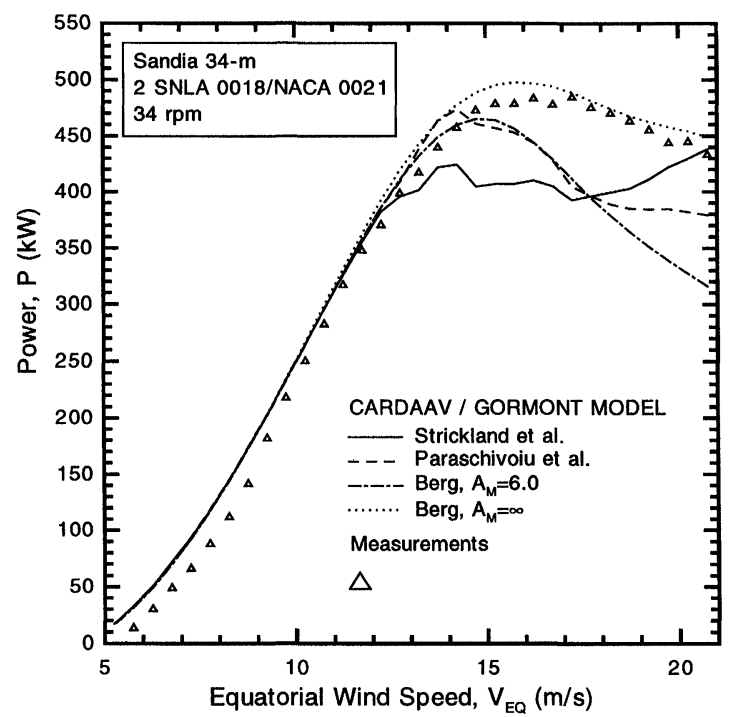

FIGURE 7 Gormont-model adaptations: Sandia 34-m at $34.0 \mathrm{rpm}$.

the implementation of Paraschivoiu et al. [1988] and by that of Berg [1983] with $A_{M}=6.0$ are, in general, very similar. The principle underlying the modifications of the Gormont model as presented by Paraschivoiu [1988] and by Berg [1983] are quite 
different but their effects on the performance predictions are similar: both models reduce the effects of the dynamic stall, but for different reasons. In the case of Paraschivoiu et al. [1988], this reduction is justified by the high turbulence level that exists in some regions of the rotor swept surface. In the case of Berg's implementation, the damping is introduced through the modification proposed by Massé [1981] which is justified by the large angles of attack that are observed over a VAWT airfoil. Discrepancies between the two models begin to be significant at large wind velocities. These differences are attributed to the neglect of the Mach number effects in the implementation of Paraschivoiu et al. [1988]. Results obtained with the implementation of Berg using $A_{M}=\infty$ are also presented. The performance predictions are largely influenced by the value of $A_{M}$.

The various comparisons suggest that the most accurate and general implementation is the one proposed by Berg [1983]. The generality of this implementation is provided by the possibility of prescribing different values of $A_{M}$. Based on the experimental data used in this paper, the optimal value of $A_{M}$ seems to be a function of the relative thickness of the airfoil. For the NACA 0015 airfoil, $A_{M}=6$ produces numerical results in good agreement with the experimental data while for both the NACA 0018 and the SNLA 0018 airfoils, $A_{M}=\infty$ is more appropriate. It is interesting to note that the value of $A_{M}$ is not a strong function of the type of airfoil (i.e. conventional or NLF airfoil). However, additional comparisons with experimental data should be undertaken in order to confirm this finding.

\subsection{Performances of Conventional and NLF Blades}

Figures 8 and 9 show the individual contributions of lift and drag to mechanical power which are expressed by Eq. (12). They have been obtained using Berg's implementation of the Gormont model with $A_{M}=\infty$, which corresponds to the most accurate implementation for airfoils having

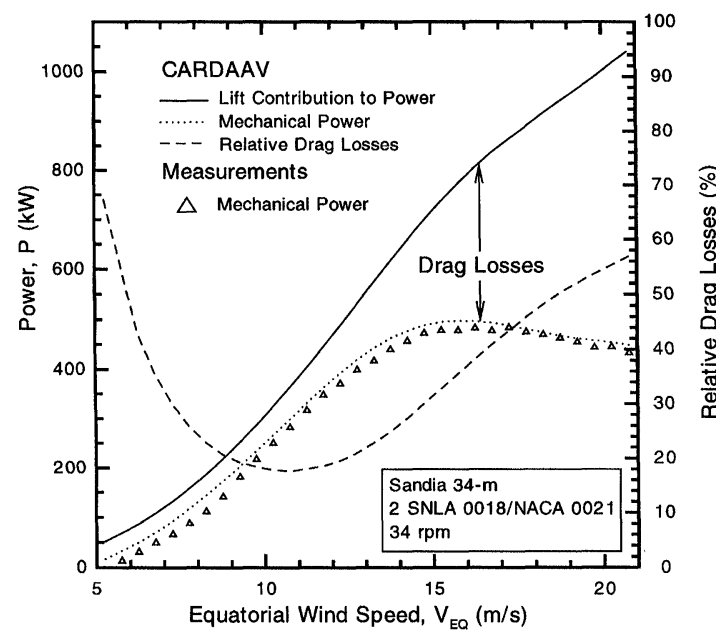

FIGURE 8 Sandia $34-\mathrm{m}$ with NLF blades at $34.0 \mathrm{rpm}$.

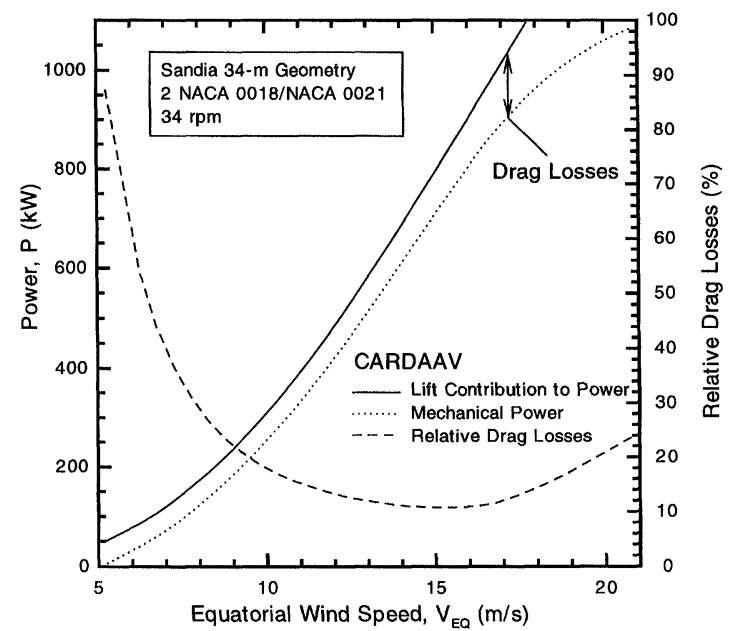

FIGURE 9 Sandia $34-\mathrm{m}$ with conventional blades at $34.0 \mathrm{rpm}$.

$t / c \geq 18 \%$. The results of Fig. 8 correspond to the performances of the Sandia 34-m rotor equipped with segmented NACA 0021/SNLA 0018 blades. The results of Fig. 9 represent the performances of an hypothetical VAWT having a geometry similar to the Sandia 34-m rotor but equipped with segmented NACA $0021 /$ NACA 0018 blades. These two figures are intended to illustrate the merits related to the use of NLF airfoils in VAWT applications. In these figures, the solid line corresponds 
to the mechanical power produced by the lift. The dotted line is the available predicted mechanical power. The difference between these two curves represents the power losses induced by the blade drag. Finally, the dashed line shows the variation of the relative drag losses, defined as the ratio of the drag losses to the lift contribution to power, with respect to the wind velocity. The corresponding scale is on the right-hand side of the figure.

A general behaviour of the VAWT operation is clearly shown in Figures 8 and 9. At low wind speeds (near $5 \mathrm{~m} / \mathrm{s}$ ), the performances of the VAWT are dominated by drag with relative drag losses reaching values as high as $90 \%$ in the case of the conventional VAWT (see Fig. 9). As the wind speed increases, the relative drag losses typically decrease and reach a minimum value of about $25 \%$ near $V_{E Q}=15 \mathrm{~m} / \mathrm{s}$. Finally, when the wind speed is further increased, the relative drag losses start to increase. This general trend is common to VAWTs equipped with conventional and NLF airfoils, but the values of the relative drag losses are different.

The high values of the relative drag losses at low wind speeds are directly related to the airfoil minimum drag: in this regime, the blades operate at very low angles of attack, well within the region where lift varies linearly and drag is essentially constant. At such low angles of attack, the lift characteristics of both conventional and NLF airfoils are similar. However, if the angle of attack is within the laminar bucket $\left(\alpha \leq \alpha_{\text {bucket }}\right)$, the NLF airfoil drag is lower than that of the conventional airfoil. This is the explanation for the lower relative drag losses produced by the blades equipped with NLF airfoils (70\% in Fig. 8) with respect to the losses induced by conventional blades $(90 \%$ in Fig. 9). The extent of this regime can be clearly identified in Fig. 10 where a compilation of the azimuthal distribution of the angle of attack at the equatorial level is presented. This figure shows the variation of the relative extent of three specific regions with respect to the complete blade cycle as a function of the wind speed. The first region comprises the locations at which the blades operate below $\alpha_{\text {bucket }}$. The second region corresponds to the

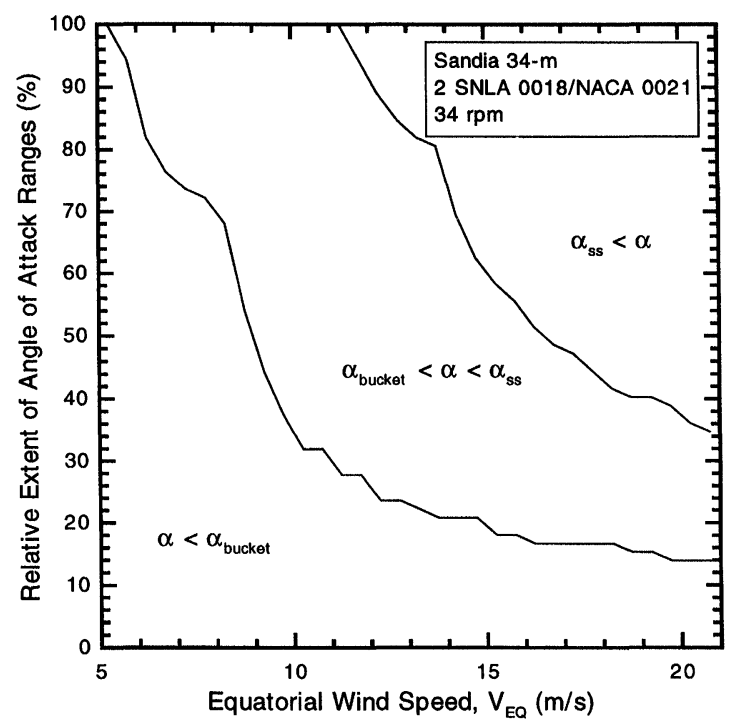

FIGURE 10 Angle of attack: Sandia 34-m at $34.0 \mathrm{rpm}$.

locations at which the blades operate in the range $\alpha_{\text {bucket }} \leq \alpha \leq \alpha_{s s}$. Finally, the third region represents the locations at which the blades operate beyond the stall angle of attack $\left(\alpha_{s s}\right)$. From this figure, we can see that the blades operate more than $90 \%$ of the time below $\alpha_{\text {bucket }}$ only for $V_{E Q} \leq 6 \mathrm{~m} / \mathrm{s}$. The extent of this regime is negligible since the angle of attack at the end of the laminar bucket $\left(\alpha_{\text {bucket }}\right)$ is typically a small value.

The existence of a region of decreasing relative drag losses is explained by the behaviour of the lift and drag characteristics between $\alpha_{\text {bucket }}$ and $\alpha_{s s}$. In this range of angle of attack, the drag coefficient presents a very weak variation while the lift coefficient is still increasing with $\alpha$. The minimum relative drag losses are reached just before the appearance of angles of attack larger than $\alpha_{s s}$. When the blades start to operate beyond the stall angle of attack, the relative drag losses begin to significantly increase with the wind speed. The point of minimum relative drag losses is located at $V_{E Q}=11 \mathrm{~m} / \mathrm{s}$ (see Fig. 8) which corresponds perfectly with the point at which the blades start to operate beyond $\alpha_{s s}$ (see Fig. 10). The value of the minimum relative drag losses reached by the rotor 
equipped with NLF blades, Fig. 8, is much larger than the one produced by the conventional rotor, Fig. 9. This is expected since the lift coefficients of the NLF airfoil are lower than those of the conventional profiles in the range $\alpha_{\text {bucket }} \leq \alpha \leq \alpha_{s s}$. Furthermore, the point of minimum relative drag losses of the NLF rotor occurs at a lower wind speed than that of the conventional rotor. This is directly related to the earlier stall of the NLF airfoil in comparison with the conventional profile.

The variations of the mechanical power produced by the NLF and conventional rotors presented in Figures 8 and 9 clearly show that the conventional airfoils are more efficient than the NLF profiles at large wind speeds. The NLF airfoils present better performances only in the very low speed range, the extent of which is negligible with respect to the operational wind speed range of the rotor. This comparison leads to the conclusion that the use of conventional airfoils results in more efficient rotors. This can be clearly understood by the study of the variation of the drag coefficients of the two types of airfoils between the stall of the NLF airfoil and the stall of the conventional profile. In this range, the drag of the NLF airfoil is much larger than that of the conventional airfoil. This increase in drag is more significant than the typical low drag characteristics within the laminar bucket of a NLF airfoil. Furthermore, the VAWT blades operate most of the time at angles of attack larger than $\alpha_{\text {bucket }}$ so that the benefits of low drag characteristics of the laminar bucket tend to be negligible. On the basis of efficiency, the conventional blades seem to be more appropriate than the NLF blades. However, additional considerations, such as the inherent control characteristics of a rotor, need to be taken into account for the successful design of a VAWT. In this respect, the SNLA 0018 NLF airfoil shows better dynamic-stall regulation characteristics than the conventional NACA 0018 profile.

The conclusions presented so far have been based on a comparison between the performances of the Sandia 34-m rotor equipped with either SNLA 0018/NACA 0021 or NACA 0018/NACA 0021 blades. In order to generalise these findings in terms of airfoils and rotor geometries, similar comparisons are presented for the Sandia 17-m rotor, Figures 11 and 12, and the Magdalen Islands rotor, Figures 13 and 14. The general behaviours of the Sandia 17-m and Magalen Islands rotors are very similar to those related to the Sandia $34-\mathrm{m}$ previously discussed.

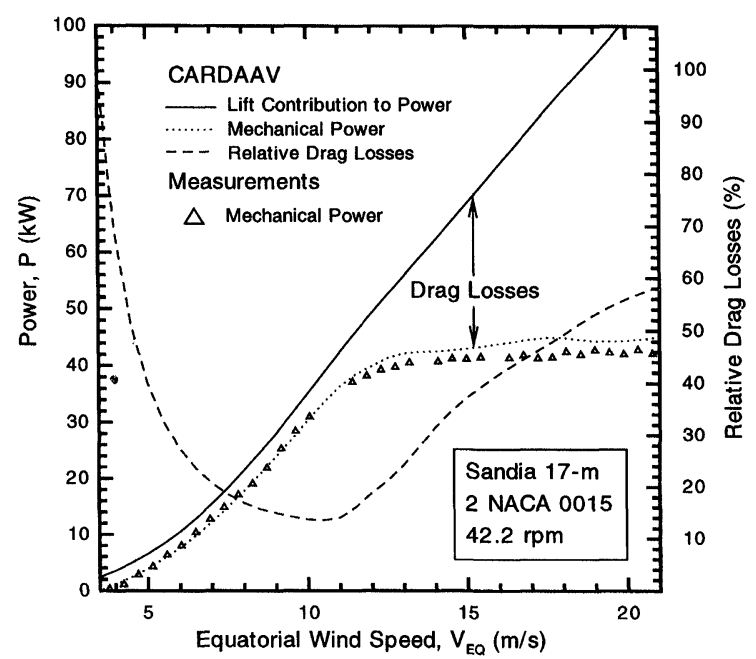

FIGURE 11 Sandia 17-m with conventional blades at $42.2 \mathrm{rpm}$.

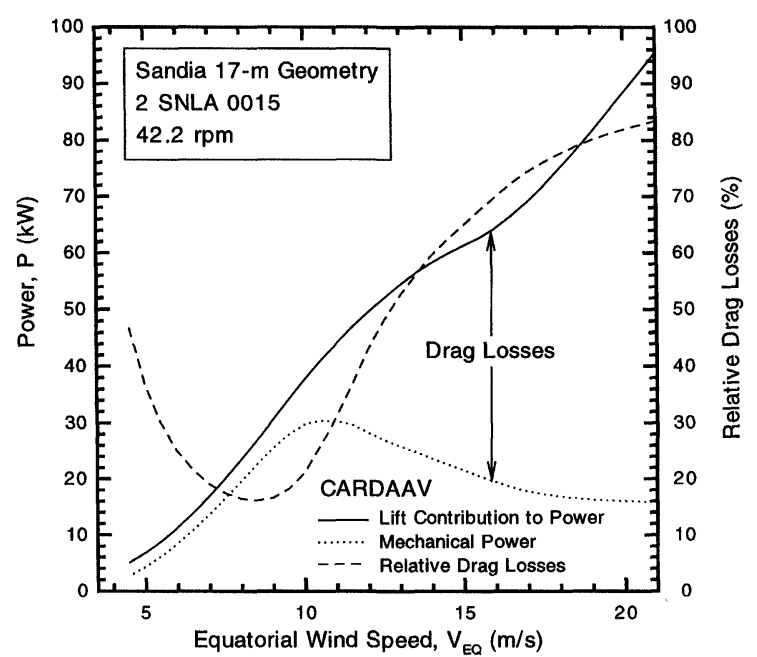

FIGURE 12 Sandia $17-\mathrm{m}$ with NLF blades at $42.2 \mathrm{rpm}$. 


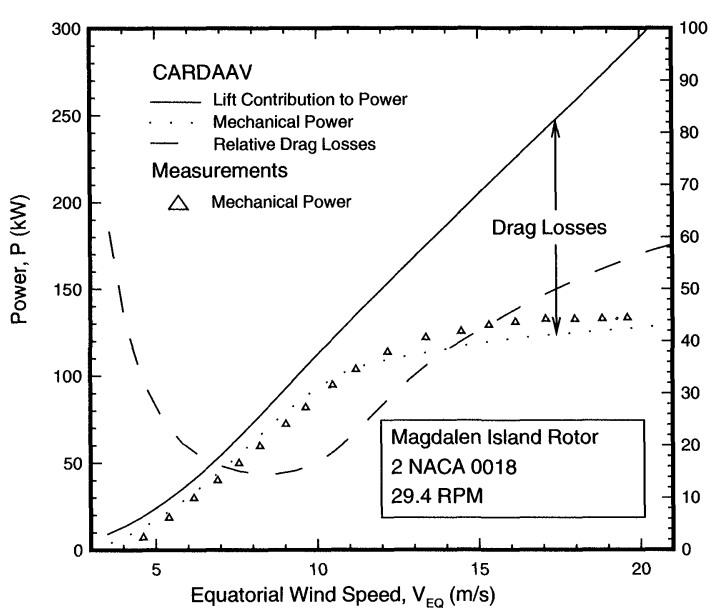

FIGURE 13 Magdalen Islands rotor with conventional blades at $29.4 \mathrm{rpm}$.

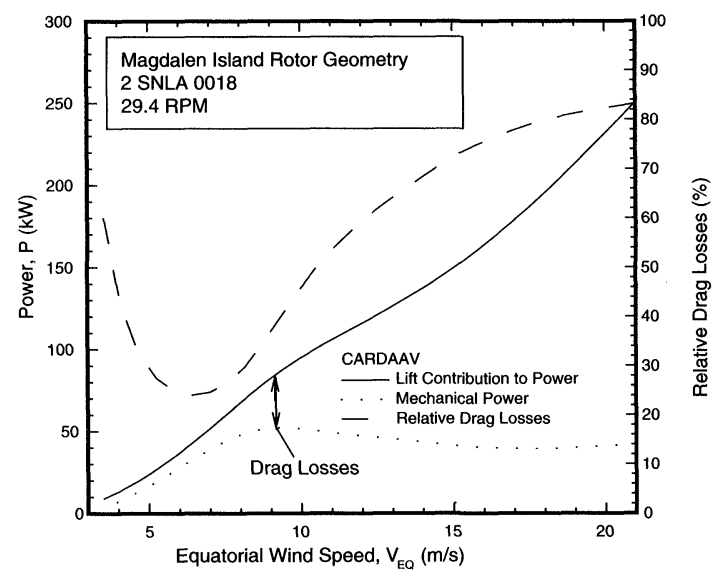

FIGURE 14 Magdalen Islands rotor with NLF blades at $29.4 \mathrm{rpm}$.

\section{CONCLUSION}

Detailed comparisons of predicted mechanical power produced by VAWTs equipped with conventional and NLF airfoils have been presented and discussed in this work. It has been demonstrated that the use of NLF airfoils can result in performance improvements with respect to conventional blades only at very low wind speeds. At relatively large wind speeds, the conventional blades are more efficient than the NLF airfoils because the significant increase in drag associated to the static stall occurs at a larger angle of attack for the former. However, the NLF blades designed at Sandia National Laboratories show better inherent dynamic-stall regulations than the symmetrical NACA airfoils at a wind speed of $15 \mathrm{~m} / \mathrm{s}$. Detailed results concerning the individual contributions of lift and drag to mechanical power have been presented. They have revealed useful insights and tips related to the successful design of VAWTs equipped with NLF airfoils.

\section{Acknowledgement}

This work is supported by the Federal Panel on Energy R \& D of Canada (PERD).

\section{References}

Berg, D.E. (1983) An Improved Double-Multiple Streamtube Model for the Darrieus-Type Vertical Axis Wind Turbine, Sixth Biennal Wind Energy Conference and Workshop, pp. 231-233.

Brochier, G., Fraunié, P., Béguier, C. and Paraschivoiu, I. (1986) Water Channel Experiments of Dynamic Stall on Darrieus Wind Turbine Blades, Journal of Propulsion and Power, Vol. 2, pp. 445-449.

Gohard, J.D. (1978) Free Wake Analysis of Wind Turbine Aerodynamics, TR 184-14, Massachusetts Institute of Technology, Cambridge.

Gormont, R.E. (1973) An Analytical Model of Unsteady Aerodynamics and Radial Flow for Application to Helicopter Rotors, U.S. Army Air Mobility Research and Development Laboratory Technical Report 72-67.

Laneville, A. and Vittecoq, P. (1985) Effect of Turbulence on Dynamic Stall, Wind Turbine Aerodynamics Seminar, Sandia National Laboratories, Albuquerque, New Mexico.

Massé, B. (1981) Description de deux programmes d'ordinateur pour le calcul des performances et des charges aérodynamiques pour les éoliennes à axe vertical, IREQ-2379.

Paraschivoiu, I. (1988) Double-Multiple Streamtube Model for Studying Vertical-Axis Wind Turbines, Journal of Propulsion and Power, Vol. 4, pp. 370-378.

Paraschivoiu, I., Désy, P. and Masson, C. (1988) Blade-Tip, Finite-Aspect-Ratio and Dynamic-Stall Effects on the Darrieus Rotor, AIAA Journal of Propulsion and Power, Vol. 2, No. 5 , pp. $73-80$

Rajagopalan, R.G. and Fanucci, J.B. (1985) Finite Difference Model for the Vertical Axis Wind Turbines, Journal of Propulsion and Power, Vol. 1, pp. 432-436.

Strickland, J.H. (1975) The Darrieus Turbine: A Performance Prediction Model Using Multiple Streamtube, SAND75-0430, Sandia National Laboratories, Albuquerque.

Strickland, J.H. Webster, B.T. and Nguyen, T. (1980) A Vortex Model of the Darrieus Turbine: An Analytical and Experimental Study, SAND79-7058, Sandia National Laboratories, Albuquerque.

Templin, R.S. (1974) Aerodynamic Performance Theory for the NRC Vertical-Axis Wind Turbine, LTR-160, National Research Council of Canada, Ottawa. 


\section{ait \\ ENERGY MATERIALS}

M A N E Y publishing

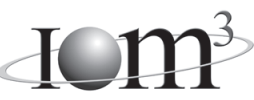

\section{Materials Science \& Engineering for Energy Systems}

Maney Publishing on behalf of the Institute of Materials, Minerals and Mining

The Institute of Materials, Minerals \& Mining

Economic and environmental factors are creating ever greater pressures for the efficient generation, transmission and use of energy. Materials developments are crucial to progress in all these areas: to innovation in design; to extending lifetime and maintenance intervals; and to successful operation in more demanding environments. Drawing together the broad community with interests in these areas, Energy Materials addresses materials needs in future energy generation, transmission, utilisation, conservation and storage. The journal covers thermal generation and gas turbines; renewable power (wind, wave, tidal, hydro, solar and geothermal); fuel cells (low and high temperature); materials issues relevant to biomass and biotechnology; nuclear power generation (fission and fusion); hydrogen generation and storage in the context of the 'hydrogen economy'; and the transmission and storage of the energy produced.

As well as publishing high-quality peer-reviewed research, Energy Materials promotes discussion of issues common to all sectors, through commissioned reviews and commentaries. The journal includes coverage of energy economics and policy, and broader social issues, since the political and legislative context influence research and investment decisions.

\section{CALL FOR PAPERS}

Contributions to the journal should be submitted online at http://ema.edmgr.com

To view the Notes for Contributors please visit: www.maney.co.uk/journals/notes/ema

Upon publication in 2006, this journal will be available via the Ingenta Connect journals service. To view free sample content online visit: www.ingentaconnect.com/content/maney

For further information please contact:

Maney Publishing UK

Tel: +44 (0)113 2497481 Fax: +44 (0)1132486983 Email: subscriptions@maney.co.uk

or

Maney Publishing North America

Tel (toll free): 8662975154 Fax: 6173546875 Email: maney@maneyusa.com

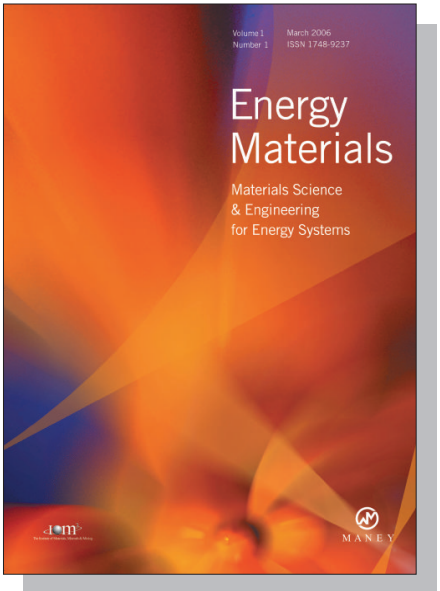

EDITORS

Dr Fujio Abe

NIMS, Japan

Dr John Hald, IPL-MPT, Technical University of Denmark, Denmark

Dr R Viswanathan, EPRI, USA

\section{SUBSCRIPTION INFORMATION}

Volume 1 (2006), 4 issues per year

Print ISSN: 1748-9237 Online ISSN: 1748-9245

Individual rate: $£ 76.00 / U S \$ 141.00$

Institutional rate: $£ 235.00 /$ US $\$ 435.00$

Online-only institutional rate: $£ 199.00 / U S \$ 367.00$

For special $\mathrm{IOM}^{3}$ member rates please email

subscriptions@maney.co.uk

\section{For further information or to subscribe online please visit www.maney.co.uk}



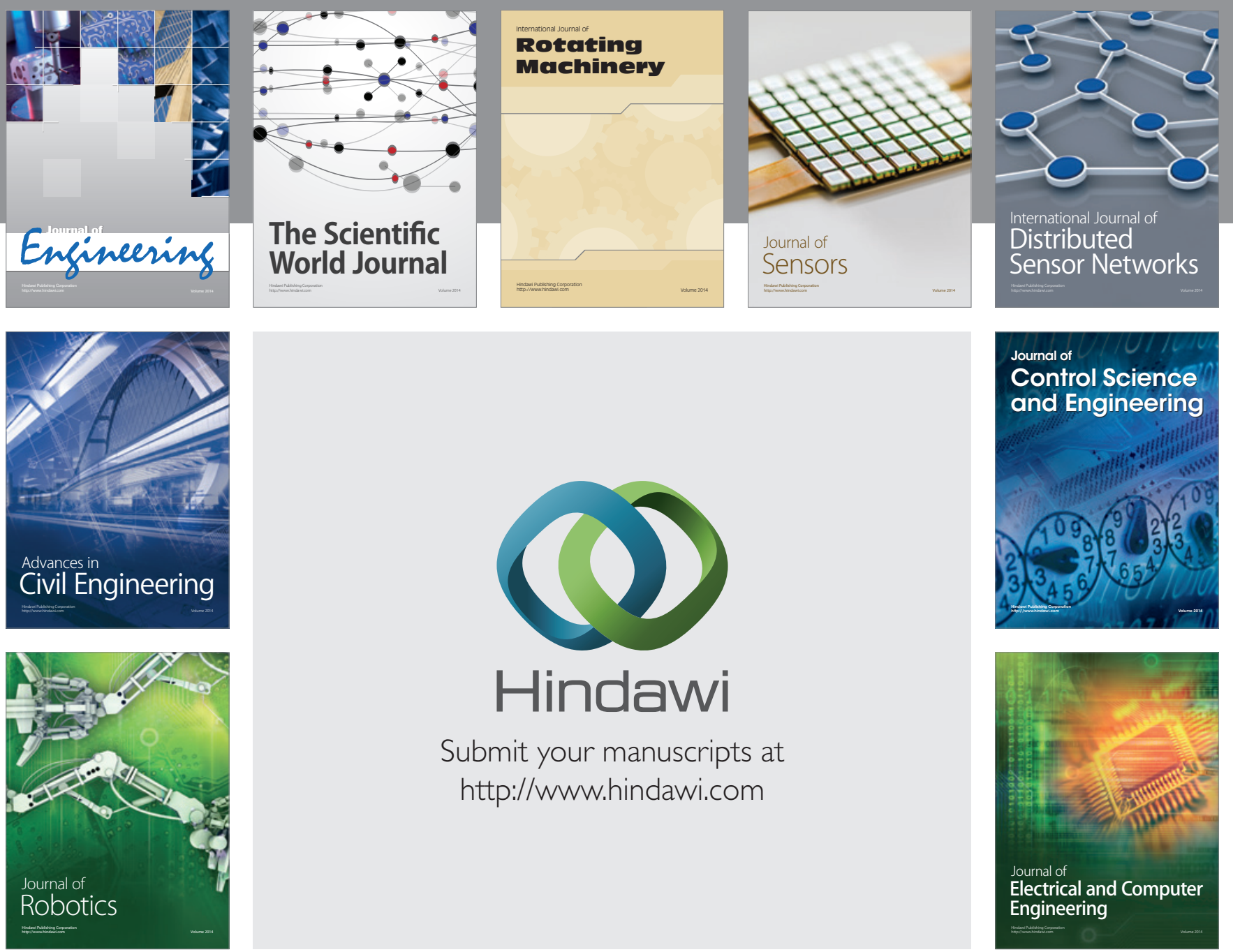

Submit your manuscripts at

http://www.hindawi.com
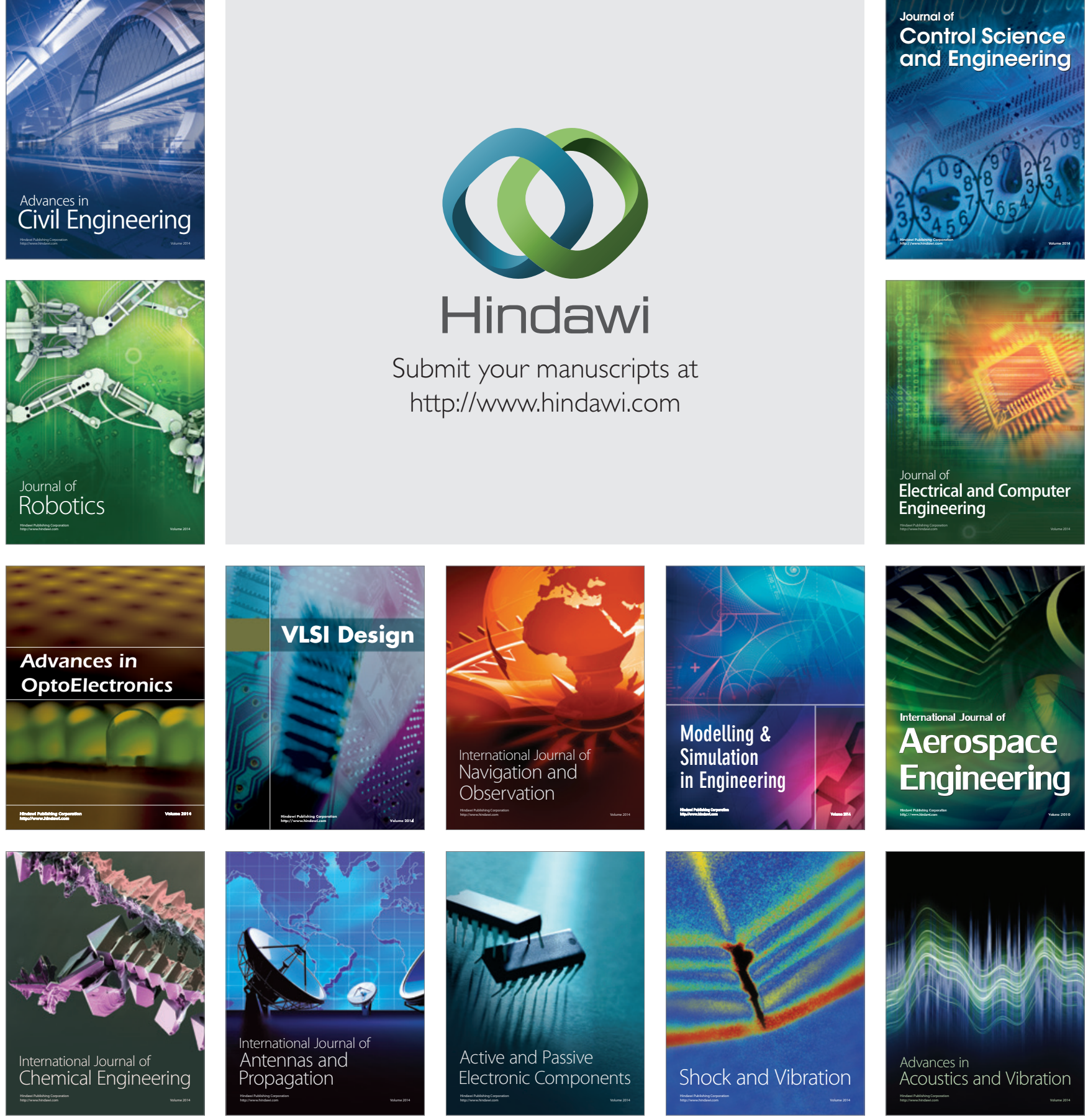